\title{
Thymoquinone Improves Motility, Plasma Membrane and DNA Integrity of Frozen-Thawed Ram Semen
}

\section{Muhammed Enes Inanc}

Burdur Mehmet Akif Ersoy University, Faculty of Veterinary Medicine, Department of Reproduction and Artificial Insemination

\section{Şükrü Güngör}

Burdur Mehmet Akif Ersoy University, Faculty of Veterinary Medicine, Department of Reproduction and Artificial Insemination

\section{Fatih Avdatek}

Afyon Kocatepe University, Faculty of Veterinary Medicine, Department of Reproduction and Artificial Insemination

\section{Deniz Yeni}

Afyon Kocatepe University, Faculty of Veterinary Medicine, Department of Reproduction and Artificial Insemination

\section{Mehmet Fuat Gülhan}

Aksaray University, Technical Sciences Vocational School, Department pf Medicinal Aromatic Plants

\section{Kemal Tuna Olğaç}

Ankara University, Faculty of Veterinary Medicine, Department of Reproduction and Artificial Insemination

\section{Barış Denk}

Afyon Kocatepe University, Faculty of Veterinary Medicine, Department of Biochemistry

\section{Umut Tasdemir ( $\nabla$ tasdemiru@gmail.com )}

Aksaray University, Faculty of Veterinary Medicine, Department of Reproduction and Artificial Insemination, Aksaray https://orcid.org/0000-0003-2827-1286

\section{Research Article}

Keywords: Thymoquinone, Nigella sativa, antioxidant, ram sperm, freezed-thawed

Posted Date: November 17th, 2021

DOI: https://doi.org/10.21203/rs.3.rs-1049539/v1 
License: (c) (i) This work is licensed under a Creative Commons Attribution 4.0 International License. Read Full License 


\section{Abstract}

This study aimed to determine the protective effects of Thymoquinone (TQ), which is the most essential active compound of Nigella sativa, on the spermatological parameters of frozen-thawed ram semen. Ejaculates were collected from five Sonmez rams. Ejaculates were extended with control $(0 \mu \mathrm{g} / \mathrm{mL} T Q)$, 10, 25, 50 and $100 \mu \mathrm{g} / \mathrm{mL}$ TQ supplemented Tris-based extender. Then extended semen samples were equilibrated in a $+4{ }^{\circ} \mathrm{C}$ cold cabinet for $2 \mathrm{~h}$. After $2 \mathrm{~h}$ the samples loaded into $0.25 \mathrm{~mL}$ French straws. The straws were then frozen by liquid nitrogen vapour and stored in a liquid nitrogen container $\left(-196^{\circ} \mathrm{C}\right)$. For analyses, frozen samples were thawed in a water bath $\left(37^{\circ} \mathrm{C}\right.$ for $\left.30 \mathrm{~s}\right)$ and evaluated in terms of motility characteristics, plasma membrane acrosome integrity (PMAI), mitochondrial reactive oxygen spices level (MITOSOX+), lipid peroxidation level (BODIPY+), DNA damage and biochemical alterations (oxidative stress index, malondialdehide and glutathione). TQ 100 had higher total and progressive motility compared to control (Pख0.05). According to motility characteristics there were significant differences between the groups on curvilinear velocity (VCL), amplitude of lateral head displacement (ALH) and linearity (LIN; Pख0.05). The highest DNA damage was detected in control groups (P凶0.05). TQ50 had higher PMAl compared to control and TQ25 (P囚0.05). The lowest MITOSOX+ level was detected in TQ50 and TQ100 groups (Pख0.05). There were no significant differences on BODIPY+, oxidative stress index, malondialdehide and glutathione $(P>0.05)$. According to results, it could be concluded that, supplementing 50 and $100 \mu \mathrm{g} / \mathrm{mL}$ TQ to Tris extender that was used for ram semen cryopreservation, showed a positive effect on motility, PMAI and also decreased DNA damage and MITOSOX+.

\section{Introduction}

Artificial insemination (Al) is the most important reproductive biotechnology for accounts an increasing proportion of farm animal reproduction, genetic potential and production (Buranaamnuay et al., 2009). The use of frozen semen in this biotechnology allows rapid selection in large populations. Sperm banking, long-term semen storage, and the possibility of storing the sperm of proven sires are the main focus objectives of using freezing the semen (Badr et al., 2010). Also, transportation of frozen semen is the most economical and easier method for performing $\mathrm{Al}$ as an assisted reproductive technique (Borah et al., 2018). Unfortunately, freezing semen can cause damage on spermatological traits such as morphological, biochemical and chromosomal status, and could be observed as reduced motility and viability (Singer et al., 1980; Badr et al., 2010). Realizing of sperm metabolism is necessary for the improvement of frozen sperm quality and development of new extender compounds for increasing frozen semen quality (Moraes et al., 2021).

Composition of extenders are important for semen quality and survival, especially after freezing-thawing process. Semen extenders usually have been composed of electrolytes (Tris, citric acid), sugars (glucose, fructose), cryoprotectants (egg yolk, glycerol) and antibiotics for several years for semen cryopreservation (Gangwar et al., 2018; Nikitkina et al., 2020). Besides these compounds, antioxidants are very important for mamalian semen freezing. The antioxidant capacity of mammalian semen is not sufficient to prevent oxidative stress during freezing (Andrabi et al., 2008; Kumar et al., 2011) The reason for this is that the 
plasma membranes of spermatozoa contain high levels of unsaturated fatty acids and lipid peroxidation due to reactive oxygen species (ROS) (Özer Kaya et al., 2018). Besides, although enzymatic and nonenzymatic antioxidants are essential compounds of the seminal plasma, their protection on oxidative events decrease due to rebuilding procedures before storage (Peris-Frau et al., 2020; Al-Mutary et al., 2021). For these reasons semen preservation studies are focus on natural antioxidants and their compounds.

Nigella $(N)$ sativa is a medicinal plant which belongs to Ranunculaceae family and generally known as black seed (Malhotra, 2004). Seeds of $N$. sativa are often used as drug, spice and food protective by people in Africa, Asia and Middle East (Goreja, 2003). It can be a valid tool for health promotion, due to its multiple mechanisms of action and low toxicity (Majdalawieh et al., 2017). Also its oil had been used for lung disease, hypercholesterolemia, artritis, stomach and intestinal health, liver and kidney function, immune system support and respiratory health (Gali-Muhtasib et al., 2006; Sharma et al., 2009). N. sativa is used by Iranians for traditional tratment of infertility (Salehi Surmaghi 2008). The studies revealed that N. Sativa oil was improved motility, semen volume, morphology, sperm count, $\mathrm{pH}$ and round cells in infertile men (Kolahdooz et al., 2014). Thymoquinone (TQ; 2-isopropyl-5-methyl-1.4-benzoquinone) a lipophilic constituent of volatile oil, is the most essantial active compounds in N. Sativa extract/oil (Shahid et al., 2018). Provious studies has shown that $N$. Sativa seeds mainly attributed Thymoquinone (30-48\%) (Burits and Bucar, 2000; Hajhashemi et al., 2004). TQ is known to be anti-inflammotory, antioxidant, neuroproduction (Radad et al., 2009) and oxidative stres induced in neuropathy (Hamdy and Taha, 2009). TQ also has inhibitory effect on the cell proliferation of cells many types of cancer (Bacak Güllü and Avci, 2013). In the literature review, some studies have been found on the quality of semen after freezing and thawing with TQ or N. sativa oil supplemented semen extender on ram, buck and buffalo semen (Awan et al., 2018; Miah et al., 2018; Shikh Maidin et al., 2018). There is only single study that TQ was used as an additive on ram semen preservation. (Miah et al., 2018). By this way, the aim of this study was to determine the exact suitable dose of TQ and revealing parts that lack information to add into the Tris extenders on cryopreserved ram semen, and evaluate effects of TQ in terms of post-thawed motility characteristics, DNA damage, biochemical alterations, plasma membrane integrity, acrosome integrity and oxidative stress parameters.

\section{Materials And Methods}

\section{Chemicals}

All chemicals were purchased from Sigma-Aldrich Chemical Co., unless otherwise stated.

\section{Animals and Fresh Semen Evaluation}

For each of the same replications, collected ejaculates with mass activity $\geq+++3$, concentration $\geq 2.0 \times$ $10^{9} / \mathrm{mL}$, volume $\geq 0.6 \mathrm{~mL}$ and motility $\geq 85 \%$ were used. A Tris-based extender ( $3.63 \mathrm{~g}$ Tris [T1503], $0.5 \mathrm{~g}$ fructose [F0127], $1.82 \mathrm{~g}$ citric acid [C0759] /100 ml bidistilled water) with 7\% glycerol (v/v), 15\% egg yolk 
was used for diluation of semen samples. Ejaculates were collected by artificial vagina from five Sonmez rams (2-3-year-old) during the breeding season in Afyonkarahisar, Turkey. In the study, fifty ejaculates were collected from rams. The ejaculates were used individually each replication for remove the ram effect.The animal use protocol of the present study was approved by the Local Ethics Committee on Animal Research, Afyon Kocatepe University (Approval number and date; 9533702/333-December 17, 2020).

\section{Semen processing}

$10 \mathrm{mg}$ of TQ (lot number; MKCC0600-274666, 298\%) was dissolved with $1 \mathrm{~mL}$ of ethanol (Merck, 99\%), and the TQ stock solution was prepared. The semen was divided into five aliquots and supplemented with $0 \mu \mathrm{g} / \mathrm{mL}$ TQ (control), $10 \mu \mathrm{g} / \mathrm{mL}$ TQ (TQ10), $25 \mu \mathrm{g} / \mathrm{mL}$ TQ (TQ25), $50 \mu \mathrm{g} / \mathrm{mL}$ TQ (TQ50), and 100 $\mu \mathrm{g} / \mathrm{mL}$ TQ (TQ100), respectively.

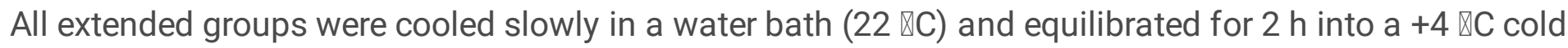
cabinet. After equilibration, extended semen groups were loaded into $0.25 \mathrm{~mL}$ French straws, frozen by using a nitrogen vapourand straws were plunged into liquid nitrogen. Then frozen samples were stored in a liquid nitrogen container $(-196 \varangle \mathrm{C})$ until to date that they were analysed. After that, samples were

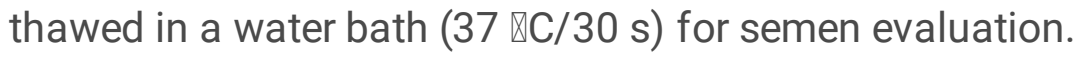

\section{Spermatozoa motility characteristics}

Spermatozoa motility characteristics were evaluated by computer assisted semen analyzer (CASA) using Sperm Class Analyzer software (SCA® v.4.2; Microptic S.L., Spain) and a connected phase-contrast microscope (Nikon Eclipse 50i; Japan). From each of frozen-thawed sample, $5 \mu$ l was taken and placed between slide and cover slide. Analyses of spermatozoa motility characteristics were done with 100x magnification, green filtered negative phase-contrast ( $\mathrm{Ph}$-). Motile spermatozoa were identified as rapid ( $>75 \mu \mathrm{m} / \mathrm{s})$, medium ( $45-75 \mu \mathrm{m} / \mathrm{s})$, slow $(10-45 \mu \mathrm{m} / \mathrm{s})$, and static $(<10 \mu \mathrm{m} / \mathrm{s})$ due to their curvilinear velocity. Spermatozoa which have $\geq 75 \%$ straightness were determined as progressive. Total motility (TMOT; \%), Progressive motility (PMOT; \%), curvilinear velocity $(\mathrm{VCL}, \mu \mathrm{m} / \mathrm{s})$, average path velocity (VAP, $\mu \mathrm{m} / \mathrm{s})$, straight line velocity (VSL, $\mu \mathrm{m} / \mathrm{s})$, amplitude of lateral head displacement (ALH, $\mu \mathrm{m} / \mathrm{s})$, beat-cross frequency $(\mathrm{BCF}, \mathrm{Hz})$, linearity $(\mathrm{LIN} \%)$ [(VSL / VCL) × 100], wobble $(\mathrm{WOB} \%)$ [(VAP / VCL) $\times 100]$, straightness $($ STR \%) [(VSL / VAP) $\times 100]$ were evaluated. A total of 200-400 spermatozoa per sample were evaluated in six microscopic zones were recorded (Olgac and Akcay, 2021).

\section{Flow Cytometric Evaluations}

The flow cytometry analyses were done by Cytoflex Flow Cytometer (Beckman Coulter, CA, USA) equipped with $525 \pm 40 \mathrm{~nm}, 585 \pm 42,610 \pm 20$ emission filters and a $50 \mathrm{~mW}$ laser output (488 nm laser beam). In each analysis, 10.000 events were examined. A side scatter area (SSC-A) versus forward scatter area (FSC-A) pseudo plot was used to exclude debris from the analysis; doublets were excluded by using Forward Scatter Height (FSC-H) and Forward Scatter Area (FSC-A) (Bucker et al., 2019). 
Working solutions of fluorescein isothiocyanate-conjugate peanut agglutinin (FITC-PNA) $[100 \mu \mathrm{g} / \mathrm{mL}$, Sigma, L7381]; Propidium iodide (PI) [2.99 mM, L7011, molecular probes, Invitrogen], 5,5',6,6'tetrachloro1,1'3,3'-tetramethylbenzimidazolyl-carbocyanine iodide (JC-1) [0.153 mM T3198, molecular probes, Invitrogen]; MitoSOX Red (5 mM; M36008, molecular probes, Invitrogen), Bodipy (5 $\mu$ M, D38611, molecular probes, Invitrogen) was prepared with DMSO and divided $50 \mu \mathrm{l}$ portions and stored $-20^{\circ} \mathrm{C}$ until use.

\section{Spermatozoa Plasma Membrane Acrosome Integrity (PMAl)}

Sperm plasma membrane acrosome integrity (PMAI) was determined using the FITC/PNA-PI staining kit according to Inanc et al. (2019). Briefly, the freeze-thawed sperm sample was diluted to $5 \times 10^{6}$ sperm in $492 \mu \mathrm{L}$ of PBS. Subsequently, $5 \mu \mathrm{L}$ of FITC and $3 \mu \mathrm{L}$ of PI were added, followed by incubation in a water bath at $37^{\circ} \mathrm{C}$ for $15 \mathrm{~min}$ in a dark room. After the incubation, the debris (non sperm) was gated out, and sperm PMAl, analyses were performed using the CytExpert 2.3 software.

\section{Mitochondrial Reactive Oxygen Species Level}

Sperm mitochondrial reactive oxygen species (ROS)level was determined using Mitosox red-propidium iodide (PI) staining according to Yeni et al. (2020). Briefly, the freeze-thawed sperm sample was diluted to $5 \times 10^{6}$ sperm in $492 \mu \mathrm{L}$ of PBS. Subsequently, $5 \mu \mathrm{L}$ of Mitosox red and $3 \mu \mathrm{L}$ of PI were added, followed by incubation in a water bath at $37^{\circ} \mathrm{C}$ for $15 \mathrm{~min}$ in a dark room. After the incubation, the debris (non sperm) was gated out, and sperm mitochondrial ROS level (MITOSOX+) analyses were performed using the CytExpert 2.3 software.

\section{Spermatozoa Lipid Peroxidation Level}

Spermatozoa lipid peroxidation level was determined using Bodipy-SYBR staining according to Korkmaz et al. (2017) protocol modification. Briefly, the freeze-thawed sperm sample was diluted to $5 \times 10^{6}$ sperm in $492 \mu \mathrm{L}$ of PBS. Subsequently, $5 \mu \mathrm{L}$ of Bodipy and $3 \mu \mathrm{L}$ of SYBR were added, followed by incubation in a water bath at $37^{\circ} \mathrm{C}$ for $15 \mathrm{~min}$ in a dark room. After the incubation, the debris (non sperm) was gated out, and spermatozoa lipid peroxidation level (BODIPY+) were performed using the CytExpert 2.3 software.

\section{Sperm DNA Damage}

Sperm DNA damage was assessed by the alkaline single-cell gel electrophoresis (COMET Assay) by Gundogan et al. (2010) method. The samples (slides) were examined under a fluorescent microscope (Olympus CX31), and the resultant images were scored using the Comet Score software (TriTek, V. 1.5). In every sample, a total of two hundred spermatozoa observed in six different zones were assessed

\section{Biochemicals Alterations}


The level of malondialdehide (MDA), indicative of lipid peroxidation, was measured in accordance with the method previously reported (Draper and Hadley, 1990). In this described method, lipid peroxides react with thiobarbituric acid and absorb at $532 \mathrm{~nm}$. The amount of MDA was calculated as $\mathrm{nmol} / \mathrm{ml}$. Glutathione (GSH) was measured spectrophotometrically at $412 \mathrm{~nm}$ and the amount was calculated as $\mathrm{mg} / \mathrm{dL}$ (Hilf and Hissin, 1976). It was used a colorimetric test kit (Relassay Diagnostics, Gaziantep, TR) for the measurement of total antioxidant status (TAS). The oxidized radical 2,2'-azinobis-(3ethylbenzothiazoline-6-sulfonic acid) (ABTS) in the kit is reduced by the antioxidant compounds in the samples and color changes are revealed. Color intensity was measured at $660 \mathrm{~nm}$ in a spectrophotometer and the results were calculated as $\mathrm{mmol} / \mathrm{L}$. It was used a colorimetric test kit (Relassay Diagnostics, Gaziantep, TR) for measurement of total oxidant status (TOS). The oxidation of reduced Fe+2 in the kit to $\mathrm{Fe}+3$ by oxidizing compounds was determined spectrophotometrically at $660 \mathrm{~nm}$ and calculated as $\mu \mathrm{mol} / \mathrm{L}$. In addition, the oxidative stress index (OSI) was calculated according to the OSI = [(TOS) / (TAS X 100)] formula (Esen et al., 2012).

\section{Statistical Analysis}

Ten replications were done in this study. The results were analyzed for normality test Shapiro Wilks and homogeneity of variance test as Levene's test. Results expressed as Mean $(X) \pm$ standard mean deviation ( \pm SD). Spermatological parameters were modelled by using the GLM procedure of SPSS 22.0 (SPSS Inc., Chicago, IL, USA). Post hoc testing was carried out for significant interactions and was performed using simple effect analysis. All statistical analyses were interpreted with a minimum error of $5 \%, p<0.05$ was considered statistically significant.

\section{Result}

Spermatozoa motility characteristics were given in Table 1. The TQ25, TQ50, TQ 100 had higher PMOT and TMOT values compared to control and TQ10 (Pख0.05). There was a significant difference between the groups in terms of VCL, ALH and LIN (Pख0.05).

TMOT, (\%), PMOT (\%), curvilinear velocity (VCL, $\mu \mathrm{m} / \mathrm{s})$, average path velocity (VAP, $\mu \mathrm{m} / \mathrm{s})$, straight line velocity (VSL, $\mu \mathrm{m} / \mathrm{s})$, amplitude of lateral head displacement $(\mathrm{ALH}, \mu \mathrm{m} / \mathrm{s})$, beat-cross frequency $(\mathrm{BCF}, \mathrm{Hz})$, linearity $(\mathrm{LIN} \%)[(\mathrm{VSL} / \mathrm{VCL}) \times 100]$, wobble $(\mathrm{WOB} \%)$ [(VAP / VCL $) \times 100]$, straightness $(\mathrm{STR} \%)$ [(VSL / VAP) $\times 100]$.

The results of DNA damage were given Table 2. According to tail length $(\mu \mathrm{m} / \mathrm{s})$ and tail DNA (\%) parameters the highest DNA damage was detected in control groups (Pख0.05).

The flow cytometric results were given in Table 3. TQ50 $(59.56 \% \pm 5.92)$ had higher PMAl compared to control $(47.77 \% \pm 1.02)$ and TQ25 (50.86\% \pm 0.99$)(P \llbracket 0.05)$. The lowest MITOSOX+ level was detected in TQ50 and TQ100 groups (Pख0.05). There were no significant differences on BODIPY+ parameters $(P>0.05)$. 
The result of OSI, MDA and GSH were given in Table 4. No significant differences were observed among the groups $(P>0.05)$.

\section{Discussion}

In the study, it has been investigated the effects of TQ supplemented Tris-based extenders on ram semen cryopreservation. Previously, TQ were generally used as food supplement or injectable treatment on mice, rats and men to evaluate its curative effects on reproductive tissues, hormonal, biochemical and spermatological mechanism. Its only a few study TQ was added to the ejaculated semen directly. At the end, it was observed that TQ had beneficial effects to improve reproductive efficiency, sperm motility, apoptosis, hormonal mechanism, biochemical parameters and oxidative status. In some studies, $N$. Sativa oil (mainly attributed TQ) and TQ was used as semen extender additive for ram, goat and buffalo semen cryopreservation and its beneficial effects on pre-freeze and post-thawed spermatological parameters were observed (Awan et al., 2018; Miah et al., 2018). But it has a lack of information about optimal doses of TQ. In the light of these information, this study is important to use TQ on ram semen cryopreservation to evaluate its beneficial and protective effects.

Motility is known as the most important indicator of fertilization ability. Jeulin et al. (1996) found a positive correlation between ALH values and fertilization in motile spermatozoa selected with the swim up technique. Besides, It was determined that the progression of spermatozoa in sheep cervical mucus was positively correlated with the VCL kinetic parameter (Robayo et al., 2008). Supported to present study by Kolahdooz et al., (2014) conducted that $5 \mathrm{~mL} N$. Sativa oil treatments was improved motility, sperm counts, $\mathrm{pH}$ and round cell in infertile men after 2 months treatment. Also TQ was improved semen quality and seminiferous tubules histopathological changes after $5 \mathrm{mg} / \mathrm{kg}$ TQ for 75 days treatments in mice (AlZahrani et al., 2012). Other supported study in male rabbit fed with $50 \%$ black seeds improved motile sperm and concentration after 29 weeks treatments (El-Tohamy et al., 2010). On the other hand, N. Sativa oil addition to ram, buffalo and buck semen extenders has improved post-thawed progressive motility and spermatozoa kinetic parameters (Awan et al., 2018; Miah et al., 2018; Shikh Maidin et al., 2018). These result also supported by Riad (2011) for improved viability, motility, DNA integrity of cryopreservation of rabbit semen with $\mathrm{N}$. Sativa extract added to extender. The present study indicated that TQ 100 had higher TMOT (53.59\%₫3.01) and PMOT (19.84\%₫1.44) compared to control and TQ10 (Pख0.05). TQ100 had highest VCL and ALH. These kinetic parameters statistically significant differences between the control group $(P<0.05)$. Apart from $10 \mu \mathrm{g} / \mathrm{mL}$ group, TQ was improved the motility compared to control. All positive effect could be explain by TQ positive effect on energy production by affect aerobic respiration with oxidative phosphorylation enzymes. Also these higher motility and velocity can be explain by neutralizing free radicals with TQ compared to control. Elimination of free radicals in the environment is thought to facilitate the ability of spermatozoa to movement.

TQ and unsaturated fatty acids are main antioxidant components of $N$. Sativa. It have been positive effect on steroidogenesis and spermatogenesis; improve positively reproductive organs and sexual hormones. These ameliorate effect was explained by promoting antioxidant defence (Mahdavi et al., 
2015). The current study about ram semen cryopreservation with different plant extract, Morignia Oleifera (Carrera-Chavez et al., 2020); Entada abyssinica (Sobeh et al., 2020); Ginger and echinacea (Meroti and Farshad, 2020) were enhances antioxidant activity and improved spermatological parameters after thawed. By this way, TQ also was demonstrated superoxide anion scavenger, androgen activities and direct cryoprotective and indirect antioxidant activities (Hala, 2011). These literature didn't support to current results for MDA, GSH, OSI and also flow cytometric lipit peroxidation level. In the present study, no siginificant differences have been found between the groups on these parameters $(P>0.05)$. At previous scientific publication about TQ and $N$. Sativa on feeding, injection and etc. These differences could be explain supplementation TQ on semen extender. For these reasons it couldn't find differences on lipid peroxidation level in extender but; statistically significant differences was detected in MITOSOX+. MITOSOX probes can determine mitochondrial ROS level (Kauffman et al., 2016). In present study, the highest MITOSOX+ level was detected in control, TQ10 and TQ 25; the lowest MITOSOX+ level was detected in TQ50 and TQ100 $(P<0.05)$. The obtained motility results show that it supports MITOSOX+ results. Both parameters TQ100 group was improved to spermatological parameters. Flagellar movement and motility of spermatozoa are provided by the energy to be produced from adenosine triphosphate (ATP) (Hallap ve ark., 2005; Gravance ve ark., 2000). Also, Kanter et al. (2010) reported that TQ can improve spermatogenesis in rat by prevent mitochondrial degeneration and antioxidant feature. By this way TQ could be react their activity to ROS by the mitochondria.

Previous studies indicated that $N$. sativa oil also favorable effects on reproductive parameters (viability and sperm morphology) in chickens and male rats (Abdulkarim and Al-Sardary 2009; Al-Saaidi et al., 2009). Woo et al. (2012) reported that TQ are mediated apoptosis induction, antiproliferation, cell cycle arrest by anti-cancer effect. Also, $250 \mathrm{mg} / \mathrm{kg} \mathrm{N}$. Sativa oil was showed decrease abnormal spermatozoa rate and increase movement and viability in sodium valproate intoxicated rats after one month (Wafaa et al. 2008). In studies conducted on semen cryopreservation, it could be observed that TQ or $N$. Sativa had beneficial effects on plasma membrane and acrosome integrity (Awan et al., 2018; Miah et al., 2018). In present study, TQ50 had higher PMAI compared to control and TQ25 (P凶0.05). According to PMAI results are supported to mitochondrial and also DNA damage status in present study. TQ50 and TQ 100 groups were protected to DNA damage compared to control in tail length and tail DNA after ram semen freezedthawed process. TQ was protected to DNA damage in Sprague-Dawley rats liver (Al-Johar et al., 2008). It has been revealed that $\mathrm{N}$. Sativa added extenders had protective roles for protection of chromosomal structure in buffalo semen cryopreservation (Awan et al., 2018). It is known that TQ induce telomere loss by reducing telomerase activity, DNA damage, apoptosis in cancerous human cell (Gurung et al., 2010). On the other hand, Wafaa et al. (2008) indicated that TQ could be use in anticancer therapeutic agent for hepatocellular carcinoma for potentially induced apoptosis (caspase 3 and 9). These positive effect could be explained by as a result of cryoprotective effect of TQ.

\section{Conclusion}

For several years $N$. Sativa extracts that are known as TQ source have been used as food intake, drug and injectable forms to improve health status. It's antioxidant and protective effects on cells and tissues has 
attracted the attention of researchers, widely. In reproduction area, N. Sativa and its extracts have been tried to improve or treat the reproductive efficiency on mice, rats and men and concluded with satisfied results. In last a few years, $N$. Sativa and TQ have been started to use in cryopreservation of semen as a new approach to profited by its antioxidant and protective features and the studies resulted with high success in terms of post-thawed spermatological traits. In conclusion, supplementing 50 and $100 \mu \mathrm{g} / \mathrm{ml}$ TQ to tris base semen extender showed a positive effect on PMOT and TMOT, PMAI and decrease DNA damage as well as MITOSOX+ level after freeze-thawing of the ram semen.

\section{Declerations}

Funding (No funding was received to assit with the preparation of the manuscript).

Conflict of Interest Statement (The authors confirm that they have no conflict of interest to declare).

Ethics approval The animal use protocol of the present study was approved by the Local Ethics Committee on Animal Research, Afyon Kocatepe University (Approval number and date; 9533702/333December 17, 2020).

Consent to participate (Not applicable).

Consent for publication (The authors agree to publish this manuscript without any concern).

Availability of data and material (Available with the permission of the authors).

Code availability (Not applicable).

Author contributions UT, MEI, DY, MFG, ŞG and FA obtained ejaculates, worked on semen processing and froze the semen. MEl and ŞG determined PMAI and flow cytometric evaluations. MEl prepared the manuscript draft. DY and FA examined spermatozoa DNA damage. MTO determined spermatozoa motility characteristics. BD specified biochemical alterations. UT designed the study edited the manuscript. All authors read and approved the manuscript.

Acknowledgements (The authors thanks to Kapucuoğlu Livestock (Afyonkarahisar, TURKEY) for the use of his facilities and flock).

Statement of animal rights (Samples were collected from clinically healthy rams during the study. No special approval was needed).

\section{References}

1. Abdulkarim, S.M., Al-Sardary, S.Y., 2009. Effect of black seed (Nigella sativa L.) on some reproductive traits in ross broiler breeder male chickens, Journal of BombayVeterinary Collage, 17(1), 19-28. 
2. Al-Johar, D., Shinwari, N., Arif, J., Al-Sanea, N., Jabbar, A.A., El-Sayed, R.A., Mashhour, A., Billedo, G., ElDoush, I., Al-Saleh, I., 2008. Role of Nigella sativa and a number of its antioxidant constituents towards azoxymethane-induced genotoxic effects and colon cancer in rats, Phytotherapy Research, 22, 1311-1323. https://doi.org/10.1002/ptr.2487.

3. Al-Mutary, M.G., 2021. Use of antioxidants to augment semen efficiency during liquid storage and cryopreservation in livestock animals: A review, Journal of King Saud University-Science, 33(1), 101226. https://doi.org/10.1016/j.jksus.2020.10.023.

4. Al-Saaidi, J.A.A., Al-Khuzai, A.L.D., Al-Zobaydi, N.F.H., 2009. Effect of alcoholic extract of Nigella sativa on fertility in male rats, Iraqi Journal of Veterinary Science, 23, 123-128.

5. Al-Zahrani, S., Mohany, M., Saleh, K., Badr, G., 2012. Thymoquinone and vitamin E supplementation improve the reproductive characteristics of heat stressed male mice, Journal of Medicinal Plants Reserch, 6(3), 493-499. https://doi.org/10.5897/JMPR11.1252.

6. Andrabi, S.M.H., Ansari, M.S., Ullah, N., Afzal, M., 2008. Effect of non-enzymatic antioxidants in extender on post-thaw quality of buffalo (Bubalus bubalis) bull spermatozoa, Pakistan Veterinary Journal, 28, 159-162.

7. Awan, M.A., Akhter, S., Husna, A.U., Ansari, M.S., Rakha, B.A., Azam, A., Qadeer, S., 2018. Antioxidant activity of Nigella sativa seeds aqueous extract and its us efor cryopreservation of beffalo spermatozoa, Andrologia, 50, e13020.https://doi.org/10.1111/and.13020.

8. Bacak Güllü, E., Avcl, G., 2013. Thymoquinone: The Bioactive Component of Nigella Sativa, Kocatepe Veterinary Journal, 6(1), 51-61. https://doi.org/10.5578/kvj.5251.

9. Badr, M.R., Abd El-Malak M.G., Hassan, H.M., 2010. Effect of trehalose on cryopreservation, oxidative stress and DNA integrity of buffalo spermatozoa, Journal of Reproduction and Infertility, 1(2), 50-57.

10. Borah, B., Deka, B., Biswas, R., Ahmed, K., Sinha, S., Chakravarty, P., Deori, S., 2018. Effect of cooling rate on quality of frozen yak semen during cryopreservation, International Journal of Chemical Studies, 6(3), 509-511.

11. Bucker, K., Malama, E., Siuda, M., Jannett, F., Bollwein, H., 2019. Multicolor flow cytometric analysis of cryopreserved bovine sperm. A tool fort he evaluation of bull fertility, Journal of Dairy Science, 102(12), 11652-11669. https://doi.org/10.3168/jds.2019-16572.

12. Buranaamnuay, K., Tummaruk, P., Singlor, J., Rodriguez-Martinez, H., Techakumphu, M., 2009. Effects of straw volume and Equex-STM on boar sperm quality after cryopreservation, Reproduction in Domestic Animals, 44, 69-73. https://doi.org/10.1111/j.1439-0531.2007.00996.x.

13. Burits, M., Bucar, F., 2000. Antioxidant activity of Nigella sativa essential oil, Phytotherapy Research, 14, 323-328. https://doi.org/10.1002/1099-1573

14. Carrera-Chavez, J.M., Jimenez-Aguilar, E.E., Acosta-Peraz, T.P., Nunez-Gastelum, J.A., QuezadaCasasola, A., Escarcega-Avila, A. M., Itza-Ortiz, M. F., Orozco-Lucero, E., 2020. Effect of Moringna oleifera seed extract on antioxidant activity and sperm characteristics in cryopreservation ram semen, Journal of Applied Animal Research, 48 (1), 114120. https://doi.org/10.1080/09712119.2020.1741374 
15. Draper, H.H., Hadley, M., 1990. Malondialdehyde determination as index of lipid peroxidation, Methods in Enzymology, 186, 421-431.

16. El-Tohamy, M.M., El-Nattat, W.S., El-Kady, R.I., 2010. The beneficial effects of Nigella sativa, Raphanus sativus and Eruca sativa seed cakesto improve male rabbit fertility, immunity and production, Journal of American Science, 6(10), 1247-1255.

17. Esen, Ç., Alkan, B.A., Kırnap, M., Akgül, Ö., Işıkoğlu, S., Erel, Ö., 2012. The effects of chronic periodontitis and rheumatoid arthritis on serum and gingival crevicular fluid total antioxidant/oxidant status and oxidative stress index, Journal of Periodontology, 83(6), 773-

779. https://doi.org/10.1902/jop.2011.110420.

18. Gali-Muhtasib, H., Roessner, A., Schneider-Stock, R., 2006. Thymoquinone: a promising anti-cancer drug from natural sources, International Journal of Biochemistry \& Cell Biology, 38, 1249-1253. https://doi.org/10.1016/j.biocel.2005.10.009.

19. Gangwar, C., Saxena, A., Patel, A., Singh, S.P., Yadav, S., Kumar, R., Singh, V., 2018. Effect of reduced glutathione supplementation on cryopreservation induced sperm cryoinjuries in Murrah bull semen, Animal Reproduction Science, 192, 171-178. https://doi.org/10.1016/j.anireprosci.2018.03.005.

20. Goreja, W.G., 2003. Black seed, Nature's Miracle Remedy, (Amazing Herbs Press, New York).

21. Gravance, C.G., Garner, D.L., Baumber, J., Ball, B.A., 2000. Assessment of equine sperm mitochondrial function using JC-1, Theriogenology, 53, 1691-1703. https://doi.org/10.1016/S0093-691X(00)003083.

22. Gundogan, M., Yeni, D., Avdatek, F., Fidas, A.F., 2010. Influence of sperm concentration on the motility, morphology, membrane and DNA integrity along with oxidative stress parameters of ram sperm during liquid storage, Animal Reproduction Science, 122, 200-207. https://doi.org/10.1016/j.anireprosci.2010.08.012.

23. Gurung, R.L., Lim, S.N., Khaw, A.K., Soon, J.F., Shenoy, K., Ali, S.M., Jayapal, M., Sethu, S., Baskar, R., Hande M.P., 2010. Thymoquinone induces telomere shortening, DNA damage and apoptosis in human glioblastoma cells, PLoS One, 5(8), e12124. https://doi.org/10.1371/journal.pone.0012124.

24. Hajhashemi, V., Ghannadi, A., Jafarabadi, H., 2004. Black cumin seed essential oil, as a potent analgesic and antiinflammatory drug, Phytotherapy Research, 18, 195-199. https://doi.org/10.1002/ptr.1390.

25. Hala, M.A., 2011. Protective effect of Nigella sativa, linseed and celeryoils against testicular toxicity induced by sodium valproatein male rats, Journal of American Science, 7(5), 687-693.

26. Hallap, T., Nagy, S., Jaakma, Ü., Johannisson, A., Rodriguez-Martinez, H., 2005. Mitochondrial activity of frozen-thawed spermatozoa assessed by MitoTracker Deep Red 633, Theriogenology, 63, 23112322. https://doi.org/10.1016/j.theriogenology.2004.10.010.

27. Hamdy, N.M., Taha, R.A., 2009. Effects of Nigella sativa oil and thymoquinone on oxidative stress and neuropathy in streptozotocin-induced diabetic rats, Pharmacology, 84, 127-134. https://doi.org/10.1159/000234466. 
28. Hilf, R., Hissin, P.J., 1976. A fluorometric method for determination of oxidized and 4 reduced glutathione in tissues, Analytical Biochemistry, 74(1), 214-226. https://doi.org/10.1016/00032697(76)90326-2.

29. Inanc, M.E., Gungor, S., Ozturk, C., Korkmaz, F., Bastan, I., Cil, B., 2019. Cholesterol-loaded cyclodextrin plus trehalose improves quality of frozen-thawed ram sperm, Veterinarny Medicina, 64, 118-124. https://doi.org/10.17221/146/2018-VETMED.

30. Jeulin, C., Lewin, L.M., Chevrier, C., Schoevaert-Brossault, D., 1996. Changes in flagellar movement of rat spermatozoa along the length of the epididymis: Manual and computer-aided image analysis, Cell Motility and the Cytoskeleton, 35, 147-161. https://doi.org/10.1002/(SICl)10970169(1996)35:2<147::AID-CM7>3.0.C0;2-7.

31. Kanter, M., 2010. Thymoquinone reestablishes spermatogenesis after testicular injury caused by chronic toluene exposure in rats, Toxicology and Industrial Health, 13, 121-127. https://doi.org/10.1177/0748233710382541.

32. Kauffman, M.E., Kauffman, M.K., Traore, K., Zhu, H., Trush, M.A., Jia, Z., Li, Y.R., 2016. MitoSOX-Based Flow Cytometry for Detecting Mitochondrial ROS, Reactive Oxygen Species (Apex), 2(5), 361370.https://doi.org/10.20455/ros.2016.865.

33. Kolahdooz, M., Nasri, S., Modarres, S.Z., Kianbakht, S., Huseini, H.F., 2014. Effects of Nigella sativa seed oil on abnormal semen quality in infertile men: A randomized, double-blind, placebo-controlled clinical trial, Phytomedicine, 21(6), 901-905. https://doi.org/10.1016/j.phymed.2014.02.006.

34. Korkmaz, F., Malama, E.,Siuda, M.,Leiding, C.,Bollwein, H., 2017. Effects of sodium pyruvate on viability, synthesis of reactive oxygen species, lipid peroxidation and DNA integrity of cryopreserved bovine sperm, Animal Reproduction Science, 128, 18-27. https://doi.org/10.1016/j.anireprosci.2017.07.017.

35. Kumar, R., Mohanarao, G.J., Arvind, Atreja, S.K., 2011. Freeze-thaw induced genotoxicity in buffalo (Bubalus bubalis) spermatozoa in relation to total antioxidant status, Molecular Biology Reports, 38, 1499-1506. https://doi.org/10.1007/s11033-010-0257-1.

36. Mahdavi, R., Heshmati, J., Namazi, N., 2015. Effect of black seeds (Nigella sativa) on male infertility: A systemic review, Journal of Herbal Medicine, 5, 133-139. https://doi.org/10.1016/j.hermed.2015.03.002.

37. Majdalawieh, A.F., Fayyad, M.W., Nasrallah, G.K., 2017. Anti-cancer properties and mechanisms of action of thymoquinone, the majör active ingredient of Nigella sativa, Critical Reviews in Food Science and Nutrition, 57, 3911-3928. https://doi.org/10.1080/10408398.2016.1277971.

38. Malhotra, S.K., 2004. Nigella, In: K.V. Peter (eds), Handbook of Herbs and Spices, vol.2. CRC Press/Woodhead Publishing Limited, Abington Hall, Abington/CambridgeCB1 6AH, England, pp. 218-226. https://doi.org/10.1533/9780857095688.391.

39. Merati, Z., Farshad, A., 2020. Ginger and echinacea extract improve the quality and fertility potential of frozen-thawed ram epididymal spermatozoa, Cryobiology, 92, 138145. https://doi.org/10.1016/j.cryobiol.2019.12.003 
40. Miah, A.G., Bathgate, R., Hamano, K., Salma, U., 2018. Effects of pre-freeze Nigella sativa oil supplementation on cryosurvival of ovine spermatozoa, Reproduction in Domestic Animals, 53, 1424-1433.https://doi.org/10.1111/rda.13656.

41. Moraes, C.R., Moraes, L.E., Blawut, B., Benej, M., Papandreou, I., Denko, N.C., Silva, M.C., 2021. Effect of glucose concentration and cryopreservation on mitochondrial functions of bull spermatozoa and relationship with sire conception rate, Animal Reproduction Science, 230, 106779. https://doi.org/10.1016/j.anireprosci.2021.106779.

42. Nikitkina, E., Musidray, A., Krutikova, A., Anipchenko, P., Plemyashov, K., Shiryaev, G., 2020. Efficiency of Tris-Based Extender Steridyl for Semen Cryopreservation in Stallions, Animals, 10, 1801. https://doi.org/10.3390/ani10101801.

43. Olğaç, K.T., Akçay, E., 2021. Effects of Spermine and Spermidine supplemented extenders on postthaw Spermatological Parameters in Stallion Semen Cryopreservation, Cryobiology, 100, 7276.https://doi.org/10.1016/j.cryobiol.2021.03.008.

44. Özer Kaya, Ş., Gür, S., Kaya, E., 2018. Effect of l-arginine addition on long-term storability of ram semen, Andrologia, 50(4), e12945. https://doi.org/10.1111/and.12945.

45. Peris-Frau, P., Soler, A.J., Iniesta-Cuerda, M., Martín-Maestro, A., Sánchez-Ajofrín, I., Medina-Chávez, D.A., Fernández-Santos, M.R., García-Álvarez, O., Maroto-Morales, A., Montoro, V., Garde, J.J., 2020. Sperm Cryodamage in Ruminants: Understanding the Molecular Changes Induced by the Cryopreservation Process to Optimize Sperm Quality, International Journal of Molecular Science, 21, 2781. https://doi.org/10.3390/ijms21082781.

46. Radad, K., Hassanein, K., Al-Shraim, M., Moldzio, R., Rausch, W.D., 2014. Thymoquinone ameliorates lead-induced brain damage in Sprague Dawley rats, Khaled Experimental and Toxicologic Pathology, $66,13-17$.

47. Radad, K., Moldzio, R., Taha, M., Rausch W.D., 2009. Thymoquinone protects dopaminergic neurons against MPP+ and rotenone, Phytotherapy Research, 23, 696700. https://doi.org/10.1016/j.etp.2013.07.002.

48. Riad, R. M., 2011. DNA Integrity, acrosomal integrity and semen characteristics following supplementation of some additives to chilled and frozen rabbit semen, Global Journal of Molecular Science, 6, 35-41.

49. Robayo, I., Montenegro, V., Valdes, C., Cox, J.F., 2008. CASA assessment of kinematic parameters of ram spermatozoa and their relationship to migration efficiency in ruminant cervical mucus, Reproduction in Domestic Animals, 43, 393-399. https://doi.org/10.1002/ptr.2708.

50. Salehi Surmaghi, M.H., 2008. Nigella sativa. In: Herbal Medicine and Herbal Therapy, 2nd ed. Donyay Taghziah Press, Tehran, Iran, pp. 216-219.

51. Shahid, F., Farooqui, Z., Khan, A.A., Oral, F.K., 2018. Nigella sativa oil and thymoquinone administration amelioratesthe effect of long-term cisplatin treatment on the enzymes of carbohydrate metabolism, brush border membrane, and antioxidant defense in rat intestine, Naunyn- 
Schmiedeberg's Archives of Pharmacology, 391, 145-157. https://doi.org/10.1007/s00210-0171444-6.

52. Sharma, N.K., Ahirwar, D., Jhade, D., Gupta, S., 2009. Medicinal and pharmocological potential of Nigella sativa: A review, Ethnobotanical Review, 13, 946-955.

53. Shikh Maidin, M., Padlan, M.H., Azuan, S.A.N., Jonit, R., Mohammed, N.H., Abdullah, R., 2018. Supplementation of Nigella sativa oil and honey prolong the survival rate of fresh and post-thawed goat sperms, Tropical Animal Science Journal, 41(2), 9499. https://doi.org/10.5398/tasj.2018.41.2.94.

54. Singer, R., Sagiv, M., Landau, B., Allalouf, D., Segenreich, E., Servadio, C., 1980. Motility and vitality of human spermatozoa at various time intervals after ejaculation, Experientia, 36, 578-579.

55. Sobeh, M., Hassan, S.A., Hassan, M.A.E., Khalil, W.A., Abdelfattah, M.A.O., Wink, M., Yasri, A. 2020. A polyphenol-rich extract from entada abyssinica reduces oxidative damage in cryopreserved ram semen, Frontiers in Veterinary Science, 7, 604477. https://doi.org/10.3389/fvets.2020.604477

56. Wafaa, A.A., Hassan, S.A., Galeb, F.M., El-Taweel, M.A., Abu-Bedair, F.A., 2008. The In vitro Promising Therapeutic Activity of Thymoquinone on Hepatocellular Carcinoma (HepG2) Cell Line, Global Veterinaria, 2(5), 233-241.

57. Woo, C.C., Kumar, A.P., Sethi, G., Tan, K.H.B., 2012. Thymoquinone: Potential cure for inflammatory disorders and cancer, Biochemical Pharmacology, 83(4), 443-451. https://doi.org/10.1016/j.bcp.2011.09.029.

58. Yeni, D., Güngör, Ş., Avdatek, F., Inanc, M.E., Taşdemir, U., 2020. Koç Spermasının Dondurulmasında Oksidatif Stres Üzerine Trolox ve Taurinin Etkisi, Mehmet Akif Ersoy University Journal of Health Science Institute, 8(3), 108-113. https://doi.org/10.24998/maeusabed.813398.

\section{Tables}

Table 1. Mean $( \pm$ SE) semen CASA motility and kinetic parameters values in frozen thawed ram semen 


\begin{tabular}{|c|c|c|c|c|c|c|}
\hline & Control & TQ10 & TQ25 & TQ50 & TQ100 & $\mathrm{P}$ \\
\hline \multicolumn{7}{|l|}{ Analysis } \\
\hline PMOT (\%) & $11.25 \pm 1.12^{\mathrm{a}}$ & $12.34 \pm 0.92^{\mathrm{a}}$ & $18.99 \pm 1.05^{b}$ & $17.30 \pm 1.71^{b}$ & $19.84 \pm 1.44^{\mathrm{b}}$ & $*$ \\
\hline TMOT (\%) & $28.80 \pm 2.40^{\mathrm{a}}$ & $30.96 \pm 2.14^{\mathrm{a}}$ & $49.46 \pm 2.38^{b}$ & $46.83 \pm 4.07^{b}$ & $53.59 \pm 3.01^{\mathrm{b}}$ & $*$ \\
\hline $\mathrm{VAP}(\mu \mathrm{m} / \mathrm{s})$ & $28.27 \pm 1.08$ & $29.39 \pm 1.17$ & $27.77 \pm 0.91$ & $27.44 \pm 1.23$ & $27.78 \pm 1.36$ & - \\
\hline VSL $(\mu \mathrm{m} / \mathrm{s})$ & $35.87 \pm 1.05$ & $37.03 \pm 1.09$ & $36.61 \pm 0.86$ & $36.10 \pm 1.15$ & $37.03 \pm 1.09$ & - \\
\hline VCL $(\mu \mathrm{m} / \mathrm{s})$ & $54.45 \pm 0.95^{\mathrm{a}}$ & $55.26 \pm 1.05^{\mathrm{ab}}$ & $56.40 \pm 0.85^{\mathrm{ab}}$ & $55.74 \pm 1.15^{\mathrm{ab}}$ & $58.48 \pm 1.32^{\mathrm{b}}$ & $*$ \\
\hline $\mathrm{ALH}(\mu \mathrm{m} / \mathrm{s})$ & $2.03 \pm 0.03^{\mathrm{ab}}$ & $2.01 \pm 0.01^{\mathrm{a}}$ & $2.15 \pm 0.04^{\mathrm{cd}}$ & $2.12 \pm 0.03^{b c}$ & $2.23 \pm 0.03^{\mathrm{d}}$ & $*$ \\
\hline $\mathrm{BCF}(\mathrm{Hz})$ & $9.69 \pm 0.91$ & $9.82 \pm 0.31$ & $9.55 \pm 0.26$ & $9.46 \pm 0.29$ & $9.96 \pm 0.36$ & - \\
\hline LIN (\%) & $46.01 \pm 1.26^{\mathrm{ab}}$ & $47.52 \pm 1.34^{\mathrm{b}}$ & $44.84 \pm 1.28^{\mathrm{ab}}$ & $44.08 \pm 1.27^{\mathrm{ab}}$ & $42.89 \pm 1.22^{\mathrm{a}}$ & $*$ \\
\hline STR (\%) & $69.23 \pm 1.00$ & $70.15 \pm 1.24$ & $67.78 \pm 1.08$ & $67.19 \pm 1.11$ & $70.15 \pm 1.24$ & - \\
\hline WOB $\mu \mathrm{m} \mathrm{s}^{-1}$ & $62.17 \pm 0.99$ & $63.48 \pm 0.93$ & $62.09 \pm 0.96$ & $61.43 \pm 0.83$ & $60.93 \pm 0.95$ & - \\
\hline
\end{tabular}

a, b, c, d Different superscripts within the same row demonstrate significant differences $(* \mathrm{P}<0.05)$

$\because$ No significant difference $(P>0.05)$

Table 2. Mean ( \pm SE) chromatin damage values in frozen thawed ram semen

\begin{tabular}{lcccccc}
\hline & Control & TQ10 & TQ25 & TQ50 & TQ100 & P \\
Analysis & & & & & & \\
\hline Tail lenght $(\mu \mathrm{m} / \mathrm{s})$ & $24.33 \pm 1.65^{\mathrm{c}}$ & $18.25 \pm 1.20^{\mathrm{b}}$ & $14.62 \pm 1.64^{\mathrm{ab}}$ & $11.95 \pm 0.69^{\mathrm{a}}$ & $11.08 \pm 1.31^{\mathrm{a}}$ & $*$ \\
\hline Tail DNA $(\%)$ & $62.89 \pm 6.38^{\mathrm{b}}$ & $55.76 \pm 6.54^{\mathrm{b}}$ & $40.20 \pm 4.33^{\mathrm{a}}$ & $34.27 \pm 1.96^{\mathrm{a}}$ & $30.17 \pm 4.14^{\mathrm{a}}$ & $*$ \\
\hline Tail moment $(\mu \mathrm{m} / \mathrm{s})$ & $17.72 \pm 1.11^{\mathrm{b}}$ & $15.50 \pm 1.78^{\mathrm{ab}}$ & $12.03 \pm 0.91^{\mathrm{a}}$ & $12.62 \pm 1.62^{\mathrm{a}}$ & $13.56 \pm 1.71^{\mathrm{ab}}$ & $*$ \\
\hline
\end{tabular}

a, b, c Different superscripts within the same row demonstrate significant differences $(* \mathrm{P}<0.05)$

Table 3. Mean $( \pm$ SE) flow cytometric results in frozen thawed ram semen 


\begin{tabular}{lcccccc}
\hline & Control & TQ10 & TQ25 & TQ50 & TQ100 & P \\
Analysis & & & & & & \\
\hline PMAI (\%) & $47.77 \pm 1.02^{\mathrm{a}}$ & $53.17 \pm 2.72^{\mathrm{ab}}$ & $50.86 \pm 0.99^{\mathrm{a}}$ & $59.56 \pm 5.92^{\mathrm{b}}$ & $54.37 \pm 2.27^{\mathrm{ab}}$ & $*$ \\
\hline MITOSOX+ (\%) & $72.88 \pm 0.65^{\mathrm{b}}$ & $73.43 \pm 0.66^{\mathrm{b}}$ & $71.73 \pm 0.88^{\mathrm{b}}$ & $66.29 \pm 5.68^{\mathrm{a}}$ & $70.58 \pm 1.01^{\mathrm{a}}$ & $*$ \\
\hline BODIPY+ (\%) & $58.83 \pm 1.39$ & $56.68 \pm 1.54$ & $61.79 \pm 2.70$ & $59.29 \pm 1.88$ & $60.92 \pm 1.79$ & - \\
\hline
\end{tabular}

a, b Different superscripts within the same row demonstrate significant differences $(* \mathrm{P}<0.05)$

-. No significant difference $(\mathrm{P}>0.05)$

PMAI: Plasma membrane and acrosome integrity, MITOSOX+: The level of mitochondrial ROS level, BODIPIY+: The lipid peroxidation level

Table 4. Mean ( \pm SE) OSI, MDA and GSH levels of frozen thawed ram semen

\begin{tabular}{llccccc}
\hline Analysis & Control & TQ10 & TQ25 & TQ50 & TQ100 & P \\
\hline MDA $(\mathrm{nmol} / \mathrm{mL})$ & $4.17 \pm 0.17$ & $3.88 \pm 0.07$ & $4.56 \pm 0.67$ & $3.95 \pm 0.19$ & $4.02 \pm 0.17$ & - \\
\hline GSH $(\mathrm{mg} / \mathrm{dl})$ & $8.38 \pm 0.09$ & $8.50 \pm 0.12$ & $8.61 \pm 0.17$ & $8.87 \pm 0.27$ & $8.92 \pm 0.33$ & - \\
\hline OSI [(TOS) / (TAS x 100)] & $22.06 \pm 2.22$ & $20.99 \pm 0.95$ & $18.69 \pm 2.76$ & $16.52 \pm 3.33$ & $19.85 \pm 0.53$ & -
\end{tabular}

-. No significant difference $(\mathrm{P}>0.05)$

The oxidative stress index (OSI), The level of malondialdehyde (MDA), The level of glutathione (GSH) 